\title{
A RELAÇÃO MARX-HEGEL: UM DESAFIO INSUPERÁVEL
}

\author{
Franklin Trein ${ }^{1}$
}

Resumo: As relações teóricas de Marx com o pensamento hegeliano têm sido objeto de permanentes discussões. Os estudiosos divergem em suas avaliações sobre o quanto e no que Marx seria devedor a Hegel. Contudo, muitos, senão a totalidade, admite que Marx iniciou suas reflexões partindo daquele que pretendeu ser o último crítico da tradição filosófica do Ocidente. Ainda que tenhamos muitos pontos de partida para a análise da relação de Marx com Hegel, a escolha do conceito de dialética nos permite percorrer um caminho particularmente rico em seus desafios e em seus resultados. Através da dialética somos levados ao centro da crítica de Marx a toda a tradição metafísica. Se o pensamento de Marx é uma teoria das relações humanas, ela fundamenta sua dimensão universal abstraindo do espaço para fazer do tempo sua referência relativa. O tempo histórico, em seu permanente movimento, constitui a realidade e seu sentido. Porém, o homem faz a história a partir de condições já existentes. Ser revolucionário é transformar o mundo a partir do entendimento do mundo.

Palavras-chaves: Hegel. Marx. Dialética. Revolução.

Résumé: Les relations théoriques de Marx avec la pensée hegeliennée est objet de discussions sans fin. Les chercheurs diffèrent dans leurs évaluations de combien et dans ce que Marx serait débiteur à Hegel. Cependant, beaucoup, sinon tous, admettent que Marx commence ses réflexions à partir de celui qui a voulu être le dernier critique de la tradition philosophique de l'Occident. Bien que nous ayons beaucoup de points de départ pour l'analyse des relations de Marx avec Hegel, le choix du concept de la dialectique nous permet avancer d'une manière particulièrement riche en défis et résultats. Grâce à dialectiques nous sommes pris au centre de la critique de Marx de toute la tradition métaphysique. Si la pensée de Marx est une théorie critique des relations humaines, elle fonde sa dimension universelle en abstrayant le space pour prendre le temps comme sa référance relative. Le temps historique, dans son mouvement permanent, constitue la réalité et sa signification. Mais l'homme fait l'histoire à partir des conditions déjà existant. Être révolutionnaire est changer le monde à partir de la compréhension du monde.

Mots-clès: Hegel. Marx. Dialectique. Révolution.

\section{Introdução}

Depois de tudo que já foi escrito sobre a relação Marx (1818 - 1883) - Hegel (1770 - 1831) e que, provavelmente, nunca se dirá uma última palavra a respeito, acreditamos que continua sendo válido se voltar a examinar este tema ${ }^{2}$.

Entre as muitas formas de tratar esta questão, aquela que encontramos com mais frequência é a que escolhe o caminho histórico, ou seja, examina em primeiro lugar os textos de juventude de Marx e pretende encontrar ali a influência de Hegel que, com o

\footnotetext{
${ }^{1}$ Graduado em Filosofia pela Universidade de Passo Fundo (1969) e doutor em Filosofia pela Universidade Livre de Berlm (1977). Pós-doutorado em Filosofia pela Universidade de Estrasburgo (1983/84) e Pós-doutorado em Relações Internacionais pela Universidade Livre de Berlim (1990). Atualmente é professor aposentado da Universidade Federal do Rio de Janeiro. Atua nas áreas de Filosofia, com ênfase em filosofia política, e Relações Internacionais, com ênfase em temas sobre a União Européia, política internacional e Mercosul.

${ }^{2}$ WOLF, Dieter. Hegel und Marx. Zur Bewegungsstruktur des absoluten Geistes und des Kapital. Hamburg: VSA - Verlag, 1979.
} 
passar dos anos, acabaria desaparecendo como fundamento epistemológico de sua visão de mundo. Esta é, por exemplo, a perspectiva de Althusser (1918 - 1990) e dos althusserianos. No entanto, não nos parece ser esta a melhor forma de tratamento do problema. Pode até ser a mais fácil, mas não será a mais consistente. Preferimos tomar outro caminho. Assim, vamos abordar a relação entre Marx e Hegel não numa perspectiva histórica, senão que numa perspectiva onto-epistemológica. Este foi o caminho que escolhemos quando construímos nossa tese de doutorado, onde fizemos uma análise crítica do que consideramos um problema entendimento na posição assumida por Althusser em suas reflexões sobre a relação entre estes dois pensadores.

Assumir o compromisso de uma análise onto-epistemológica significa, desde de logo, enfrentar uma questão complexa. Examinar a construção e o conteúdo de conceitos, quanto se percorre textos que, mesmo pertencendo a teorias distintas, com frequência, contém palavras idênticas para nomear coisas diferentes, pode levar a grandes equívocos. Normalmente, as formas mais frequentes de leitura na perspectiva histórica confundem a palavra com o conceito que a nomeia. Ou seja, dito de outro modo, ali se mistura, de forma indistinta, o nome com o homem. Como sabemos, é possível chamar de Pedro muitos homens diferentes. Contudo, receber um mesmo nome não significa dever ou poder ser confundido com o seu homônimo. No nosso entendimento é de que é isto o que acontece, com frequência, quando se examina a relação entre Marx e Hegel. Pois, encontramos no pensamento de ambos algumas mesmas palavras, mas seus conteúdos são radicalmente distintos ${ }^{3}$.

Para demonstrar o que pretendemos, deve ser dito que, primeiro, não existiria um Marx sem antes ter existido um Hegel e, segundo, ao afirmarmos isto, de modo algum significa que estamos admitindo que Marx tenha sido simplesmente mais um hegeliano em qualquer momento da construção de sua filosofia. Assim, a opção pelo caminho da análise de alguns conceitos no pensamento de Marx e Hegel é o que se impõe para as nossas reflexões no presente texto.

Como ponto de partida tomamos o conceito de dialética. Poderia ser outro, mas este conceito tem estado no centro de muitas críticas à relação entre Marx e Hegel. Ao examinar o que Hegel entende por dialética e o que a dialética significa no pensamento de Marx, acreditamos que se terá a oportunidade de apresentar o que acabamos de

\footnotetext{
${ }^{3}$ RUBEN, Peter. Methodologische Bemerkungen zur Beziehungen zwischen Logik und Dialektik bei Hegel und Marx. Online-Edition peter-ruben.de.

\begin{tabular}{|c|c|c|c|c|}
\hline Ronista Dialectus & Ano 3 & n. 8 & Janeiro - Agosto 2016 & p. 33-59 \\
\hline
\end{tabular}
}


anunciar, ou seja, que Marx resgatou o conceito de dialética na filosofia de Hegel, porém sem com isto se deixar iludir pela carga metafísica do conceito hegeliano. ${ }^{4}$

\section{$\mathrm{O}$ conceito de dialética na filosofia de $\mathrm{Hegel}^{5}$}

Dialética, desde Heráclito $(535$ - 475) de Éfeso, é movimento, e isto vale também para Hegel. Mas não somente um movimento abstrato, no pensamento, onde os conceitos se sucedem dando curso ao processo de conhecimento, ou ainda, dito de outra forma, de apreensão da realidade pelo ato de pensar. Se partirmos da conhecida relação sujeito - objeto, identificamos o movimento dialético, em primeiro lugar, no próprio objeto, isto porque, para Hegel, a dialética não é só método, mas lógica; em outros termos, ela é expressão radical da natureza ontológica do objeto como realidade em permanente movimento. ${ }^{6}$

Podemos afirmar que, para Hegel, o objeto, a coisa, a realidade, é dialética, está animada de um constante vir-a-ser, onde as partes se relacionam dialeticamente. $\mathrm{Na}$ ontologia hegeliana a realidade objetiva está em ininterrupto processo de constituição. Para os iniciados em filosofia poderíamos dizer que, discordando de Aristóteles e se aproximando de Platão, Hegel afirma que jamais nos encontramos diante do ser (Sein), e sim de que a realidade é um permanente sendo (Seiendes) ${ }^{7}$. Na Ciência da Lógica, de forma explicita, Hegel se refere a este modo de ser da coisa como o movimento dialético da substância (dialektische Bewegung der Substanz). ${ }^{8}$

O segundo movimento da dialética está no conceito ${ }^{9}$. O conceito, como forma abstrata de apreensão do objeto, se modifica junto como o próprio objeto. Isto tem

\footnotetext{
${ }^{4}$ MARX. Nachwort zur zweiten Auflage (des Kapitals). Berlin: MEW, Band 23, p. 27.

WAGENKNECHT, Sahra. Vom Kopf auf die Füße? Zur Hegelkritik des jungen Marx oder das Problem einer dialektisch-materialistischen Wissenschaftstheorie. Bonn: Pahl-Rugenstein Verlag, 1997.

5 KIMMERLE, Heinz (Hrsg). Modelle der materialistischen Dialektik - Beiträge der Bochumer Dialektik-Arbeitsgemeinschaft. Den Haag: Martius Nijhoff, 1978.

${ }^{6}$ HEGEL. Vorlesungen über die Philosophie der Religion I. Fankfurt am Main: Suhrkamp Verlag, Bd. 16, 1969, p. 159.

${ }^{7}$ HEGEL. Vorlesungen über die Geschcihte der Philosophie II. Fankfurt am Main: Suhrkamp Verlag, Bd. 19, 1971, p. 11 - 249.

${ }^{8}$ Sustância, para Hegel, é o que é permanente na coisa. Em sua constante atividade ela é origem de seus acidentes, portanto os acidentes não são separados de sua substância e esta não é para além daqueles. $\mathrm{O}$ conceito de substância pode ser encontrado ao longo de toda a extensa obra de Hegel, mas é na Ciência da Lógica onde ele ganha seu conteúdo mais denso, sem perder sua extensão. Passagens significativas para este texto podem ser lidas na Wissenschaft der Logik II, Band 6, S. 217 e S. 246, da edição da Suhrkamp Verlag.

${ }^{9}$ Conceito (Begriff) é um termo, um elemento, na filosofia de Hegel que por sua especificidade, por suas
}

\begin{tabular}{|c|c|c|c|c|}
\hline Revista Dialectus & Ano 3 & n. $\varepsilon$ & Janeiro - Agosto 201 & p. 33-59 \\
\hline
\end{tabular}


implicações de grande relevância. Se o objeto se modifica dialeticamente e o conceito acompanha suas mudanças; o conceito não será jamais uma verdade completa do objeto. A verdade estará sempre em construção.

Terceira consequência. Quando examinamos o problema da verdade ${ }^{10}$ em Hegel, não podemos falar propriamente de erro, pois o erro faz parte da construção da verdade. O erro é um momento importante da verdade, uma vez que a verdade é exatamente a sua superação, por oposição dialética. A verdade, se se quiser, como verdade positiva, se constrói como uma contradição em relação ao erro. A verdade só é verdade na medida em que ela contém a não-verdade como o algo que foi ultrapassado (aufgehoben).

Se dialética é movimento, então o que provoca o movimento? O que impulsiona o estado atual em direção ao devir? Hegel responde que a mola da dialética é a contradição. Ele distingue entre contradições objetivas e contradições subjetivas. Estas últimas são as contradições do pensamento ou as contradições nos conceitos. São subjetivas ainda as contradições que ocorrem no ato de pensar. Contudo, a consciência não se sente confortável diante de uma contradição e, assim, se move num impulso (Trieb) que lhe permita superar a contradição do seu pensar ou de seu pensamento. $\mathrm{O}$ movimento da consciência, que é igualmente um movimento na consciência, é sempre uma superação dialética (Aufhebung). Desta forma, o novo conceito significa superação, mas também conservação, o que implica em uma nova contradição. Em outras palavras, o movimento do conceito e no conceito é a apreensão de superações sucessivas das contradições que lhes são próprias. Dito ainda de outro modo, as contradições subjetivas são o modo de ser permanente da consciência.

características muito próprias, exclusivas na história da filosofia, oferece enormes dificuldades de entendimento. Não é aqui o lugar para qualquer tentativa de esclarecimento do que é conceito para Hegel. Contudo, que nos seja permitido observar que o conceito, ao qual nos referimos no texto destas breves considerações tem como conteúdo o objeto que ele apreende, ou seja, uma realidade fora dele, da qual ele se aproxima mais e mais em sua constituição. Um texto particularmente revelador do conteúdo do conceito no entendimento de Hegel é sua carta a Niethammer de 10 de outubro de 1811.

${ }^{10}$ A exemplo de outros elementos constitutivos da especificidade da filosofia hegeliana, o que Hegel entende como verdade é algo complexo e distinto da tradição filosófica. A verdade, como substantivo (die Wahrheit), encontra-se em íntima relação com um outro substantivo, o (que é) verdadeiro (das Wahre), ambos com origem no adjetivo verdadeiro (wahr), que neste caso tem a força insubstituível de qualificar aquilo que é. Assim, encontramos em Hegel a compreensão de que algo é porque é verdadeiro, como ainda de que algo é, porque (verdadeiramente) falso. Esta breve observação está longe de esgotar o problema do conteúdo da verdade, pois, como nos adverte Hegel no § 571 da Enzyklopädie der philosophischen Wissenschaften, a verdade é objeto da filosofia, ou seja, é um conceito a ser pesquisado ao longo de toda a sua obra!

\begin{tabular}{|l|l|l|l|l|}
\hline Q Rovista Qialectus & Ano 3 & n. 8 & Janeiro - Agosto 2016 & p. 33-59 \\
\hline
\end{tabular}


As contradições objetivas, negadas por Kant (1724 - 1804), têm em Hegel uma realidade mais complexa, elas ganham várias gradações. Enquanto contradição objetiva ela pode ser uma oposição radical, o que chamamos de contrário; ela pode ser também uma divergência parcial, o que chamamos de contraditório, e pode, ainda, se apresentar como uma simples alteridade. Hegel nos dá exemplos. Mais (+) e menos (-), na natureza, na eletricidade, são contrários, ou seja, diferentes, mas um depende do outro. Sol e chuva são contraditórios, ou seja, diferentes, mas um não depende do outro. Porém, algo pode estar ainda em oposição dialética simplesmente pelo fato de ser outro que não o mesmo. Estas diferentes manifestações da contradição podem estar separadas, uma a uma, ou reunidas, como contradição dialética, em uma mesma coisa. O que importa é que, como contradição, será, ou serão responsáveis pelo movimento, pelo impulso que levará a uma superação da condição, do estado presente, pois nada é, definitivamente.

Mas, se falamos de superação, como entender superação em si, como entender aquele conceito difícil de traduzir, que toma formas tão distintas nas muitas línguas para as quais foram passadas as obras de Hegel e do Marxismo? O conceito a que nos referimos, no original em alemão, tem nome de Aufhebung. Como devemos entender a Aufhebung como movimento, como superação dialética, como entender a síntese como a nova forma assumida pelo objeto e seu conceito? - como a forma do momento seguinte ao abandono da forma anterior para dar lugar à nova forma?

A resposta a estas perguntas é importante, porque até aqui tudo que foi dito para a dialética de Hegel, com o devido cuidado, poderia ser dito para a dialética de Marx. Entretanto, isto estará correto somente se tomarmos em consideração que o sentido da Aufhebung, da superação dialética da contradição em Marx, é completamente outro do que a de Hegel.

É precisamente aqui, no nosso entendimento, um dos momentos em que o materialismo de Marx se separa do idealismo de Hegel. Para Hegel o movimento da dialética tem uma finalidade e tem um fim, ou seja, um termo, ou um término, e tem a razão de ser em si mesmo.

Esclarecendo:

- A finalidade do movimento da dialética é a realização da potência do Espírito absoluto, como destinação da história humana.

\begin{tabular}{|l|l|l|l|l|}
\hline Qevista Qialectus & Ano 3 & n. 8 & Janeiro - Agosto 2016 & p. 33-59 \\
\hline
\end{tabular}


- O fim, é simplesmente o fim, sua realização plena, o telos, uma vez que a história não é um processo eterno, embora possa durar muito tempo. Hegel admite que, como a história teve um momento inicial, ela também terá o seu momento final.

A prova, para Hegel, de que a história não é eterna é o fato de que há progresso e, na lógica da dialética, não há condições de um progresso sem um limite. O fim em si mesmo está no fato de que os homens, como portadores da história, do movimento da história, reproduzem, de alguma forma, cada um na sua existência, o movimento histórico de todos os homens, da humanidade. E Hegel não desconhece, em nenhum momento, que os homens são naturalmente mortais. Para Hegel a humanidade é parte da natureza e com a natureza ela tem um sentido, uma finalidade, um fim!

\section{A dialética em Marx}

Para Marx o movimento de superação dialética se dá na relação entre as coisas, entre as partes que constituem o todo da realidade apreendida em sua história. Não há uma origem humana do homem e nem um destino, menos ainda um destino sobrehumano - um fim no futuro - não há finalidade - ditada de fora da relação entre as

coisas e entre os homens, que se relacionam entre si através das coisas, ou seja, como forças produtivas e em suas relações de produção. Para Marx o homem é o responsável por sua história, e somente ele. Não há uma força estranha, externa, transcendente, determinando o ontem, o hoje, ou o amanhã de cada individuo e de toda a humanidade.

O movimento da história, como superação das contradições, tem como fio condutor o mesmo princípio estabelecido por Darwin (1809 -1882). E é Darwin, melhor do que qualquer outro, quem nos ensina que a natureza se desenvolve de acordo com suas próprias leis e as leis da natureza estão nela mesma. Em Marx aprendemos que, na história, as contradições seguem suas leis de natureza, às quais a vontade e a intervenção humana não se sobrepõem, senão que nelas estão contidas, simplesmente.

Feitas esta breves observações sobre a dialética em Hegel e Marx. Sigamos um pouco mais adiante.

\section{A filosofia da história de Hegel}

A filosofia da história de Hegel não é recolhida do Idealismo Alemão na sua forma original deixada por Kant (1724 - 1804). Entre o filósofo de Könisberg e o

\begin{tabular}{|l|l|l|l|l|}
\hline Q Povista Dialectus & Ano 3 & n. 8 & Janeiro - Agosto 2016 & p. 33-59 \\
\hline
\end{tabular}


último e maior representante do Idealismo se interpõem, pelo menos, duas contribuições que preparam o palco em que se apresentará o grande espetáculo filosófico da realidade, uma peça em muitos atos, que começa com a Fenomenologia do Espírito(1807) e conclui com Os Princípios da Filosofia do Direito (1820): primeiro Fichte (1762 1814) e logo a seguir Schelling (1775 - 1854).

Fichte, embora não discorde inteiramente de Kant, quando aceita a ideia de um plano da história, que tem como fio condutor a liberdade, no entanto, por entendê-la demasiado contingente dos acontecimentos, se afasta da perspectiva kantiana. Se devemos partir de um plano a priori, o desenvolvimento da história só terá consistência na medida em que cumpra o sentido de uma necessidade lógica. Esta, porém, não se revela na contingência dos fatos, mas no movimento dinâmico do conceito, ou seja, na estrutura lógica do conceito, que na verdade, para Fichte, é quem sustenta a própria força do movimento histórico. ${ }^{11}$

Schelling se revela ainda mais radical do que Fichte. Ele parte do suposto de que todo o real é cognocível. O que pode ser dito ainda como todo o real é manifestação de uma razão absoluta e ao real pertence tanto a natureza como a história.

É Coolingwood (1889 - 1943) quem nos esclarece melhor esta relação presente na filosofia de história de Schelling. Ele observa que a natureza, se ela é inteligível, será necessário que um sujeito a conheça para que assim ela se revele em sua essência. Esta relação entre o sujeito e seu objeto é a manifestação mais completa da razão absoluta. Ou ainda, o próprio espírito é, a um só tempo, sujeito e objeto. Mas não é suficiente o espírito conhecer a natureza. Deste modo a história continuaria incompleta. O espírito deve conhecer também a si mesmo. "A história é um processo temporal em que tanto o conhecimento como o objeto cognocível se forma progressivamente. É o que se exprime, chamando à história a auto-concepção do Absoluto, representando este a razão, quer como objeto quer como sujeito." 12

Se tomarmos em conta que a Geschichtsphilosophie de Hegel só foi composta nos primeiros anos da década de 20 do século XIX, estaremos advertidos de que se trata

\footnotetext{
${ }^{11}$ FICHTE, I.H. Zur Politik, Moral und Philosophie. In: Fichtes Werke Bd. VII. Bonn: Walter Gruyter \& $\mathrm{Co}, 1971$.

LAUTH, Reihard. Der Begriff der Geschcichte nach Fichte. In: Philosophisches Jahrbuch, 72 (1964/65).

${ }^{12}$ SCHELLING, F.W.J. Grundlegung der Positiven Philosophie. Torino: Bottega D’Erasmo, 1972. COLLINGWOOD. R.G. A ideia de História. Lisboa: Editorial Presença, 2001, p. 182.

\begin{tabular}{|c|c|c|c|c|}
\hline Revista Dialectus & Ano 3 & n. $\varepsilon$ & Janeiro - Agosto 201 & p. $33-59$ \\
\hline
\end{tabular}
}


de uma obra da maturidade; ela é do mesmo período de seus Esboços da Filosofia do Direito. A filosofia da história, na verdade, recolhe e sintetiza todo o sistema filosófico de Hegel. Isto é suficiente para nos dizer da extensão e da complexidade desta unidade na filosofia hegeliana. Para Hegel a filosofia da história é a própria história como conhecimento de si mesma. A história, da qual fala a filosofia, não são acontecimentos empíricos senão que conceitos. A razão domina a história que se realiza racionalmente na história do mundo, uma história cujo fim é o de que o Espírito alcance o conhecimento disto que ele é verdadeiramente e, ao mesmo tempo, faça este conhecimento produzir de forma concreta um mundo existente verdadeiro enquanto objetivo. Mas qual o caminho a seguir? Hegel responde, o caminho está dado pela liberdade do homem que é o mesmo que a consciência que ele tem de sua liberdade. ${ }^{13}$

Se o sistema da filosofia e a filosofia da história se confundem, em certa medida, é de interesse lembrar algumas características do primeiro. O ponto de partida do sistema coincide com o seu término; a relação entre finito e infinito se resolve na identidade do racional com o real - disto decorre a sincronia entre a história como acontecer empírico e a realização do conceito como Ideia. O sistema da filosofia está composto pela história da arte, da religião e da filosofia tanto como formas como momentos do Espírito absoluto. A filosofia da história, por sua vez, é o saber, a consciência, de cada uma daquelas formas, daqueles momentos e da totalidade da qual cada um é uma parte.

Para Hegel quando a história parece ser uma trama de fatos contingentes, é porque a consciência que a examina escolheu uma perspectiva do intelecto finito, isto é, individual. O mundo existente é manifestação do Espírito, é o Espírito do mundo, objetivamente presente em cada povo, que é parte de um todo, momento de um único Espírito universal.

A história para Hegel supõe uma consciência que a anote. Esta consciência deve cumprir a dupla dimensão de consciência de si e de consciência para si. Ela deve registrar os eventos em seus movimentos e suas contradições e reter ainda a sua própria condição de consciência como consciência da história. Só assim ela será também consciência histórica. A isto deve ser acrescido que, a rigor, só o mundo humano tem

\footnotetext{
${ }^{13}$ STICH, Herta. Von Herds "Ideen zur Philosophie der Geschichte der Mensacheit" über Kant, Fichte, Schelling bis zu Hegels Vorlesungen über Philosophie der Geschichte. Ein Beitrag zur Philosophie der Geschichte. Wien, Philosophische Diskussion, 1936 (mimeo).
}

\begin{tabular}{|l|l|l|l|l|}
\hline Q Povista Dialectus & Ano 3 & n. 8 & Janeiro - Agosto 2016 & p. 33-59 \\
\hline
\end{tabular}


história, e ainda não todo ele, mas somente aquelas sociedades nas quais foi possível que alguma consciência desenvolvesse a capacidade de realizar-se plenamente, enquanto tal, isto é, como consciência e autoconsciência, condição necessária para entender e anotar o movimento da história em sua contradição.

Para alguns críticos, como Inwood ${ }^{14}$, na filosofia hegeliana a natureza não tem história. A natureza só se desenvolveria e sofreria mudanças de modo cíclico. Desta compreensão discordam muitos outros leitores Hegel. Em primeiro lugar pode ser lembrado Friedrich Engels (1820 - 1895). Em suas obras - entre as mais conhecidas Herrn Eugen Dühring Umwälzung der Wissenschaft (Anti-Dühring) e Die Dialektik der Natur $^{15}$, Engels faz exaustivas referências a Hegel como aquele filósofo da moderna filosofia alemã que teve o mérito de compreender que "todo o universo da natureza, da história e do espírito se descreve como um processo, ou seja, como determinado por um movimento constante, em permanente mudança, transformação e evolução."16 Jean Hyppolite (1907 - 1968), para fazer referência ao mais importante representante do pensamento hegeliano na tradição filosófica francesa, concorda com Engels. Diz ele: "Em Hegel a história realiza no tempo a ideia de Absoluto, como a natureza a realiza no espaço."17

Na concepção de mundo de Hegel, ainda que se deva distinguir duas diferentes dimensões da realidade, uma da natureza e outra do homem, ou seja, o que é natural e o que é cultural, há entre elas um continuo ôntico-ontológico que autoriza atribuir à realidade no seu todo uma mesma definição de história. É Henri Lefebvre (1991 - 1991) que, ao analisar a historicidade em Hegel, nos adverte:

\begin{abstract}
A história se define. Em toda definição, e neste caso em particular, há um fim, sob um tríplice aspecto: a) finitude, ou seja determinação e limitação do processo, a delimitação inerente às condições disto nasce no movimento; b) finalidade, ou seja orientação, sentido (duplo: objetivo e/ou subjetivo), destinação ou destino anunciado, devir previsível entretanto surpreendente, em síntese, inteligibilidade sob as contingências superficiais; c) finição: ou seja conclusão, perfeição, segundo o modelo da arte (conclusão e perfeição conforme à natureza ou à essência da coisa, portanto formas adequadas a seu conteúdo).
\end{abstract}

\footnotetext{
${ }^{14}$ INWOOD. M. Dicionário Hegel. Rio de Janeiro: Jorge Zahar Editor, 1997, p.161.

15 As duas obras de Engels citadas - Anti-Dühring e Dialética da Natureza - estão reunidas no volume de $\mathrm{n}^{\circ} 20$ da coleção MEW, Berlin: Dietz Verlag, 1972.

${ }^{16}$ ENGELS. Anti-Dühring. Berlin: MEW, Band 20, p. 22.

${ }^{17}$ HYPPOLITE, J. Ruse de la raison et histoire chez Hegel. In: Figure de la pensée philosophique.
} Paris: PUF, 1971, p. 151

\begin{tabular}{|l|l|l|l|l|}
\hline Q Rovista Qialectus & Ano 3 & n. 8 & Janeiro - Agosto 2016 & p. 33-59 \\
\hline
\end{tabular}


Três aspectos igualmente necessários e racionais (necessários à razão e segundo a razão). Inseparáveis. Nenhuma conclusão, nenhuma perfeição sem a finitude que o romantismo deplora. Nenhuma finalidade sem a orientação (sentido) inerente ao devir criador, que fixa os seus propósitos, inconscientes ou conscientes. ${ }^{18}$

Para Hegel a história se move dialeticamente, o que significa dizer que ela termina a cada momento para dar lugar a um novo ciclo. Ela conclui seu movimento ao ser negada. Assim, cria espaço para um novo período que também terá o seu próprio fim. O motor que impulsiona a história se alimenta de suas contradições. No entendimento de Hegel a lógica dialética é o fio condutor da história e a lógica para o filósofo não diz respeito só a um método de pensar, mas também ao modo de ser do que é pensado. O pensado como conteúdo do pensamento não existe apenas na cabeça do sujeito que pensa. Isto significaria reduzir a filosofia a um idealismo subjetivo. As ideias, se elas constituem o pensamento dos sujeitos é porque estes têm a capacidade de pensar. Mas, por sua vez, se as ideias, na forma de realidade objetiva, não estivessem também fora da cabeça de quem pensa, por assim dizer, o pensar não teria seu objeto. Isto significa que no entendimento de Hegel tanto o pensar quanto o pensado se pertencem mutuamente. Dito ainda de outro modo: a realidade um, a natureza, nas partes que a constituem, tem nos conceitos que nomeiam seus elementos constitutivos uma dimensão ontológica necessária; por sua vez, a realidade dois, a cultura, tem nas coisas nomeadas pelos conceitos uma origem indispensável, sem as quais estes seriam vazios. Tal condição confere ao conceito - um constructo - uma dupla dimensão de subjetividade e objetividade, uma vez que um não pode existir sem o outro.

$\mathrm{O}$ que os sujeitos pensam e o que eles fazem expressa a lógica da ideia. No pensar e no agir humano se revela a direção e o sentido da história. Para Hegel não existe uma história independente da humanidade como não existe uma humanidade fora da história. A história do mundo se realiza através dos indivíduos com sua razão e suas paixões. Ao se moverem, os homens realizam o sentido da história sem autoconhecimento ou intenção - ser histórico é da realidade do ser homem -. O que está implícito nas paixões e nas vontades individuais se realiza tanto mais quanto mais aquelas paixões e vontades de seus portadores estejam em conformidade com o espírito de seu povo (Volksgeist). Hegel identifica na tradição o lugar das vontades, mas a

${ }^{18}$ LEFEBVRE, H. La fin de l'histoire. Paris: Les Éditions de Minuit, 1970, p.22

\begin{tabular}{|c|c|c|c|c|}
\hline Qenista Dialectus & Ano 3 & n. 8 & Janeiro - Agosto 2016 & p. 33-59 \\
\hline
\end{tabular}


tradição não é só conservação, ela é também movimento, é progresso, instrumento dos homens heroicos, daqueles que corporificam a história do mundo (Weltgeschichte). O herói é o homem, que movido por sua vontade e por suas paixões se faz expressão da história do mundo de seu tempo, ele é a própria verdade da história, é síntese dialética do universal - o conceito - e do singular - o seu povo. Suas vitórias são as melhores expressões da verdade histórica que eles representam. Na filosofia hegeliana toma o nome de astúcia da razão (List der Vernunft) o fato de o Espírito do mundo (Weltgeist) se valer dos indivíduos e de suas paixões para realizar seus fins.

Hegel insiste em apresentar sua tese de que a realização da Ideia na história passa, necessariamente, pelas consciências individuais. A Ideia e sua realização, o mundo, não são duas realidades distintas, são duas dimensões, dois momentos formando um mesmo todo. A ação dos indivíduos também é ambivalente. Ela cumpre tanto uma finalidade singular quanto universal. Assim, com uma face subjetiva e outra objetiva, os indivíduos dão substância à dialética da história como dialética do real. Para Hyppolite Hegel aprendeu com Adam Smith (1723- 1790) que os indivíduos, perseguindo seus interesses próprios, ao final acabam realizando um projeto coletivo, que se encontra além dos limites da singularidade de cada um, que é a produção de riqueza material como um bem social, apropriado individualmente. Neste sentido a história não é o lugar de realização da felicidade individual, mas um destino inexorável. Enquanto tal, na história os indivíduos realizam outra coisa do que aquilo que eles acreditavam querer, porém o que eles realizam não lhes é completamente estranho. Há sempre no fazer de cada um uma ambiguidade, e é sempre este o espaço ocupado pelos grandes vultos da história. Os grandes homens são aqueles que realizam a vontade geral em cumprindo com o seu destino de individuo ${ }^{19}$.

Na filosofia de Hegel os indivíduos e os povos são momentos da contradição dialética que move a história do Espírito, e a história do Espírito é a sua realização como conhecimento de si próprio - autoconhecimento. Os homens são simples portadores - Träger - da dialética que anima o movimento do Espírito na construção da autoconsciência. Os povos são sempre transitórios. Eles passam, perdem sua importância, são superados na dialética da história do mundo. Quem foi vencido pela contradição é porque perdeu o sentido maior do Espírito do mundo. Um povo será

${ }^{19}$ HYPPOLITE. . Ruse de la raison et histoire chez Hegel. In: Figure de la pensée philosophique. Paris: PUF, 1971, p.153 e 154 .

\begin{tabular}{|l|l|l|l|l|}
\hline Q Revista Dialectus & Ano 3 & n. 8 & Janeiro - Agosto 2016 & p. 33-59 \\
\hline
\end{tabular}


dominador só pelo tempo em que for o mais lúcido quanto ao movimento do Espírito objetivo. Mas, no embate dialético, a derrota não é a aniquilação. Aquele que cedeu seu lugar, ainda que na margem da história, continuará presente. A síntese é tanto superação quanto conservação. É uma Aufhebung, ou seja, nada se aniquila, nada desaparece. A história é a realização de todas as existências.

Ainda na Filosofia do Direito Hegel apresenta a tese de que o fim último da história é a realização da liberdade ${ }^{20}$ do Espírito e que o lugar privilegiado desta realização é o Estado. A realização da liberdade, porém, vai além da consciência. Tem na autoconsciência o ponto de partida necessário, mas ainda insuficiente. A verdadeira liberdade está além da condição de singular. Assim, na filosofia hegeliana o Estado se converte em fim supremo de todos os homens. É o lugar onde eles encontram uma existência racional e onde eles agem no cumprimento de uma vontade universal. Só no Estado as artes, a religião e a filosofia podem encontrar sua plena liberdade, condição necessária ao seu completo desenvolvimento. Ou ainda, só no Estado a história universal do mundo pode alcançar sua plena liberdade e sua objetividade.

Outra vez é Hyppolite quem observa:

[...] é necessário assinalar aqui a profunda influência de Rousseau sobre Hegel. Rousseau inspira o tema do Estado como encarnação da vontade universal, portanto como ideia realizada na história e suscetível de ser desejada como tal. Ao lado da sociedade civil, que é a sociedade dos homens privados, incapazes de querer diretamente o universal, Hegel põe o Estado no qual o cidadão deseja o universal. $\mathrm{O}$ Estado será então a liberdade realizada na história, aquela comunidade que, em transcendendo a sociedade civil, será a obra absoluta da humanidade. ${ }^{21}$

No pensamento de Hegel a história se apresenta como paradoxal: sem passado nem futuro seu movimento acontece todo no presente. Deste modo ela é expressão ontológica radical do ser e ela só pode ser apreendida na sua única forma, que é sendo.

Estas breves observações sobre como Hegel entende a história nos permite afirmar que a visão de mundo de Marx não poderia convergir e, menos ainda, coincidir com o idealismo hegeliano. Para darmos reforçarmos esta tese, vejamos, brevemente, o que Marx nos diz sobre a história.

\footnotetext{
${ }^{20}$ Neste sentido Hegel fala da história como história universal. Ver: HEGEL. Princípios da Filosofia do Direito, $\S 341$ e seguintes.

${ }^{21}$ HYPPOLITE. . Ruse de la raison et histoire chez Hegel. In: Figure de la pensée philosophique. Paris: PUF, 1971, p. 155.
}

\begin{tabular}{|l|l|l|l|l|}
\hline Q Rovista Qialectus & Ano 3 & n. 8 & Janeiro - Agosto 2016 & p. 33-59 \\
\hline
\end{tabular}




\section{Marx e a História}

Para um exame do entendimento de Marx sobre a história, nada mais conveniente do que analisar o seu texto. Neste sentido, nos deteremos, especialmente, na Ideologia Alemã, onde podemos ler:

Nós conhecemos uma única ciência, a ciência da história. A história pode ser contemplada de dois lados, dividida na história da natureza e na história dos homens. Os dois lados não podem ser separados. Enquanto existirem homens, a história da natureza e a história dos homens se condicionam mutuamente. A história da natureza, a assim chamada história natural, não nos diz respeito aqui. Contudo, a respeito da história dos homens, teremos de trata-la, uma vez que a ideologia inteira se reduz ou a uma compreensão invertida dessa história ou à abstração total dela. A ideologia, ela mesma, é apenas um dos lados dessa história. ${ }^{22}$

A primeira frase deste parágrafo é, talvez, um dos momentos mais originais e, por isto mais densos do pensamento marxista. E aqui deve ser dito marxista e não só de Marx, uma vez que se ao longo de sua obra, juntamente com Engels, ele insistiu em construir os fundamentos de uma ciência da história, aquela que diz respeito à história dos homens, e ciência da história poderia ser, muito bem, sinônimo de marxismo, tomado como o pensamento de Marx e Engels. Se Marx pretendeu ocupar-se somente da história dos homens, sabemos que Engels não só o acompanhou o tempo todo como ainda fez algumas incursões no que eles chamam aqui de história da natureza, ou história natural.

Marx, em seus estudos de matemática ${ }^{23}$, dá a entender que, em algum momento, poderia aproveitar os conhecimentos de Engels sobre a natureza na elaboração de uma reflexão de caráter epistemológico, que chegou a anunciar como a lógica do Capital, onde, é possível, que pretendesse unir o movimento da história humana à história da natureza, fazendo da primeira só um capítulo do longo processo de evolução da própria natureza. Engels foi muito mais longe do que Marx no seu esforço de aproximar as duas histórias e assim devolver o homem a natureza. Na obra a Dialética da Natureza ele

\footnotetext{
${ }^{22}$ MARX, ENGELS. Die deutsche Ideologie, Berlin: MEW, Band 3, p.18.

${ }^{23}$ MARX, ENGELS. Mathematische Manuskripte.Wolfgang Endmann (Hrsg.). Kronberg: Scriptor Verlag, 1974.

\begin{tabular}{|l|l|l|l|l|}
\hline Qevista Dialectus & Ano 3 & n. 8 & Janeiro - Agosto 2016 & p. 33-59 \\
\hline
\end{tabular}
}


desenvolve a tese de que, na natureza, a evolução se faz movida pelo mesmo princípio que impulsiona a história humana, ou seja, o da contradição dialética.

Hoje, sabemos o quanto aquela obra foi objeto de críticas, tanto de cientistas quanto de filósofos, entre os quais cabe lembrar a contribuição de Sartre, uma das mais contundentes e mais densas em seus argumentos contra Engels ${ }^{24}$. Também é conhecido o fato de que Marx acompanhou e elaboração da Dialética da Natureza em todos os seus momentos e, pelo quanto que sabemos, nunca fez qualquer observação ao pensamento de Engels, nem a favor e nem contra. O que é certo, contudo, é que Engels defendeu as mesmas teses expostas na Dialética da Natureza em outros momentos de sua obra, ainda que não tão extensamente, e que nestas outras exposições Marx colaborou diretamente. Entre elas, por sua relevância, dois textos merecem ser citados: o Anti-Düring e o Ludwig Feuerbach.

Voltemos ao início do texto citado da Ideologia Alemã: Nós conhecemos uma única ciência, a ciência da história. Qual é o desafio contido nesta tese? Primeiro: todo conhecimento se reduz a uma única ciência. Segundo: esta única ciência é uma ciência da história. Até aqui parece tudo muito simples. Nós sabemos o que é conhecimento, nós sabemos o que é ciência, ou pelo menos temos a pretensão de saber o que significam estes conceitos. O que falta então é saber o que é história. Marx e Engels não nos dizem o que entendem por história na forma da definição de um verbete de dicionário. $\mathrm{O}$ que eles entendem por história esta construído ao longo de uma obra que foi escrita no decorrer de mais de quatro décadas e seus registros somam dezenas de milhares de páginas. Considerando sua extensão, não seria uma tarefa fácil recolher as partes que compõem o conceito de história no pensamento marxista. Acontece, entretanto, que para além da quantidade de textos onde deveríamos pesquisar sobre o conteúdo do conceito, deveríamos ter em conta ainda que o marxismo se constitui numa crítica radical a todo o pensamento tradicional da filosofia no Ocidente. Ele é muito mais do que a sua negação, do que o seu contrário, ele é o fundamento ontoepistemológico de uma nova visão de mundo, de uma nova filosofia que, se assumida, põe abaixo todo o grande edifício do saber científico, que começou a ser construído

\footnotetext{
${ }^{24}$ SARTRE. Critique de la raison dialectique. Paris: Librairie Glimard, 1960, p. 129 - 135. SCWARZ, Th. J.-P. Sartre et le marxisme. Réflexions sur la Critique de la raison dialectique. Lousanne: L'Âge de l'Homme, 1976.

\begin{tabular}{|c|c|c|c|c|}
\hline Ronista Dialectus & Ano 3 & n. 8 & Janeiro - Agosto 2016 & p. 33-59 \\
\hline
\end{tabular}
}


muito antes da contribuição deixada pelos gregos, ao longo dos cinco séculos, que antecedem o início da tradição metafísico-cristã.

Não tomarmos de imediato o caminho sugerido pelos autores - Marx e Engels para a apreensão do conceito de história, vamos examinar primeiro o que é a ideologia, uma vez que a ideologia inteira se reduz ou a uma compreensão invertida dessa história (da história dos homens) ou à abstração total dela. Esta observação antecipa um elemento importante do conceito, que é central para o fundamento da visão de mundo de Marx.

- Primeiro: história supõe movimento, movimento no tempo. Mas o tempo é uma abstração, ele só se torna concreto quando referido ao espaço, assim, história é o acontecer numa relação espaço-temporal.

- Segundo: o movimento, permanente, não obedece a uma lei dialéticomecanicista, como pretende Popper $(1992-1994)^{25}$, na sua crítica estreita a Hegel e Marx, pelo contrário, se constrói a cada momento como resultado do livre-arbítrio, da liberdade, da constante mudança do sujeito e do objeto e das relações dialéticas entre ambos. Seria uma ingenuidade, injustificável na teoria de Marx, crítico do idealismo de Hegel, quando resgata o sendo no lugar do ser, não tê-lo destituído de sua destinação, de sua dimensão teleológica.

A história como movimento é resultado de duas estruturas paralelas e entrelaçadas, uma, a infraestrutura, que acontece segundo suas probabilidades (e ninguém construiu melhor esta filosofia da natureza do que Darwin ${ }^{26}$ ) - o mecanicismo, como ação e reação é uma percepção própria da metafísica - e a outra, a superestrutura, que acontece como realização da liberdade. Como veremos, o homem, para Marx, é o responsável pela significação que toma a realidade em cada momento da história. $\mathrm{Ou}$ em outras palavras, a história não é uma realidade em si na qual o homem se encontra mergulhado e dissolvido, e da qual ele deva emergir para apontá-la com sua teoria. A história se realiza na dupla dimensão de fato e feito, de acontecimento e significação. No desvão entre o acontecido e o sentido que lhe atribui o homem é que se constrói a compreensão ideológica da história como compreensão invertida desta história. Por isto

\footnotetext{
${ }^{25}$ POPPER, K. Das Elend des Historizismus. Tübingen: Mohr Siebck Verlag, 2003. POPPER, K. Die offene Gesellschaft und ihre Feinde. Tübingen: Mohr Siebck Verlag, 2003.

${ }^{26}$ DARWIN, Ch. A Origem das Espécies. Rio de Janeiro: Ediouro, 2004.

\begin{tabular}{|l|l|l|l|l|}
\hline Qevista Dialectus & Ano 3 & n. 8 & Janeiro - Agosto 2016 & p. 33-59 \\
\hline
\end{tabular}
}


é que a crítica da ideologia se oferece como um fio condutor privilegiado até o conteúdo da própria história.

A tese de Marx não é só de que a ideologia é uma apreensão invertida da história, senão que, ainda, a de que a ideologia é o resultado dialético das condições de existência do próprio homem: condições materiais e espirituais.

Terceira observação: ao examinarmos o pensamento de Hegel nos deparamos com uma dificuldade bastante conhecida e não desprezível. A forma do texto hegeliano, por sua estrutura complexa e pela densidade de conteúdo contido em cada conceito, dificulta a leitura e a assimilação de cada elemento da argumentação do filósofo, seja na sua parte como parte, seja na sua parte como todo. Mas, ao final, uma vez apreendida cada parte, o todo se faz coerente, completo e conforme uma tradição bem conhecida, embora crítico a ela. Hegel não se situa além da metafísica, senão que no seu ponto culminante.

Com Marx a situação é radicalmente outra. Como ele mesmo adverte na $\mathrm{XI}^{\mathrm{a}}$ tese sobre Feuerbach (1804 - 1872) : "Os filósofos só interpretaram o mundo diversamente, trata-se pois de transformá-lo." Ou seja, para Marx a construção de uma fillosofia, de uma visão de mundo, perde o seu caráter especulativo e ganha um sentido prático. Admitir e acompanhar a construção de uma teoria que se declara, desde o seu ponto de partida, voltada à transformação da realidade e entender que para cumprir com este objetivo ela tenha que ser verdadeira, abandonando todas as muitas versões que se construíram sobre a realidade, porque todas elas apoiadas em falsas premissas, é o desafio maior e muito mais difícil do que entender o sistema hegeliano de ver o mundo. Com Marx a filosofia deixa a sua falsa neutralidade diante do mundo, ela abandona a comodidade da teoria que pensa a realidade como o acontecido. A filosofia e seu objeto se realizam em um só e mesmo tempo. Teoria e prática se entrelaçam sem se confundir, disputando uma posição sempre mais avançada no acontecer da história. Isto é o que constitui seu caráter revolucionário.

Retomemos o texto ou o caminho trilhado por Marx. Seu ponto de partida não é a referência a Bruno Bauer na Questão Judaica, onde fez a crítica de uma crítica abstrata.

\begin{tabular}{|l|l|l|l|l|}
\hline Q Povista Dialectus & Ano 3 & n. 8 & Janeiro - Agosto 2016 & p. 33-59 \\
\hline
\end{tabular}


O primeiro pressuposto de toda a história humana, nos diz Marx, é naturalmente a existência de indivíduos humanos vivos. ...O primeiro ato histórico, destes indivíduos, pelo qual eles se distinguem dos animais, não é que eles pensem, senão que comecem a produzir seus meios de vida. ...Produzindo seus meios de vida, os homens produzem, indiretamente, sua própria vida material. ${ }^{27}$

Diferentemente da tradição metafísica, o ponto de partida aqui não é o ser da ontologia, nem o sujeito de conhecimento da gnosiologia, mas o homem concreto que, talvez, possa ser feito objeto de uma antropologia filosófica. O indivíduo humano concreto é agora de onde parte a filosofia. É um ponto de partida concreto, legitimo, porque universal e singular, integral e integrado à realidade.

O que significam estes adjetivos referidos ao sujeito como ser humano e ponto de partida do entendimento filosófico da história?

- Concretos: são os seres humanos como indivíduos vivos, reais.

- Legítimos: eles se distinguem dos demais seres animados porque se sabem parte e todo.

- Universais: eles são responsáveis, cada um, por toda a história humana.

- Singulares: são os seres humanos que reproduzem seres de sua espécie e produzem ainda suas condições materiais de vida.

- Integral: não podem ser somente parte e, por mais forte razão, somente todo.

- Integrado: ao fazerem a história a integram

Quando Marx observa que: “O que os indivíduos são, portanto, dependes das condições materiais de sua produção", de fato, ele inicia uma breve argumentação através da qual nos apresenta, numa perspectiva histórica, as condições sociais de produção da vida. Sublinha que, de um lado, a complexidade das condições de produção leva a uma divisão do trabalho, segundo diferentes categorias, e de outro resulta em diferentes formas de propriedade. Um pouco mais a frente ele conclui: " $O$ fato, portanto, é o seguinte: indivíduos determinados, que como produtores atuam de um modo também determinado, estabelecem entre si relações sociais e políticas determinadas"

${ }^{27}$ MARX, ENGELS. Die Deutsche Ideologie. Berlin: MEW, Band 3, p. 20-21.

\begin{tabular}{|c|c|c|c|c|}
\hline Q Rovita Dialectus & Ano 3 & n. 8 & Janeiro - Agosto 2016 & p. 33-59 \\
\hline
\end{tabular}


Ao contrário do que sempre pretendeu todo o pensamento idealista, afirma Marx, "não é a consciência que determina a vida, senão que a vida é que determina a consciência". ${ }^{28}$ Assim,

[...] devemos começar pela premissa básica de toda a existência humana, portanto, de toda a história; ou seja, a de que os homens devem estar em condições de viver para poder fazer história. Mas à vida corresponde primeiramente o comer e o beber, a habitação, o vestuário e ainda outras coisas. A primeira realidade histórica é, pois, a produção dos meios para a satisfação daquelas necessidades, a produção da própria vida material, e isso constitui um dado histórico, uma condição fundamental de toda a história que, hoje ainda, como há milhares de anos devemos executar dia a dia, hora a hora, para simplesmente mantermos os homens com vida ... O fundamental de toda a concepção da história é, portanto, observar o fato decisivo em todo o seu significado e em toda a sua extensão e deixá-lo assumir a sua verdadeira importância. ${ }^{29}$

Na produção social de suas vidas, os homens aceitam, com toda a certeza e necessariamente independente de suas vontades, as relações de produção que são correspondentes a um determinado grau de desenvolvimento material de suas forças produtivas. A totalidade de tais relações de produção constitui a estrutura econômica da sociedade, a sua base real, sobre a qual se erguem as superestruturas jurídicas e políticas, correspondentes, por sua vez, a uma determinada forma de consciência social. O modo de produção da vida material determina a vida social, política e intelectual em geral. ${ }^{30}$

Esta compreensão da história, segue Marx, refere-se, por conseguinte, ao desenvolvimento do processo real de produção, partindo da produção material da vida imediata, e às relações humanas produzidas por tal processo e a ele vinculadas; ou seja, a sociedade burguesa em suas diferentes etapas, entendida (aqui) como fundamento de toda a história (moderna) e apresentada assim em sua ação, enquanto Estado, explica o conjunto das diversas produções teóricas e das formas de consciência, religião, filosofia, moral etc., que lhe são próprias e o processo de formação das mesmas....não explica a prática a partir das ideias, mas sim a formação das ideias a partir da prática. ${ }^{31}$

Em outro momento Marx completa dizendo:

Toda a concepção de história, até hoje, desconsiderou completamente esta verdadeira base da história ou então tratou-a tão somente como uma coisa secundária, totalmente desvinculada do desenvolvimento histórico... a verdadeira produção da vida aparece (ali) como não histórica, enquanto que histórica é aquilo que está desligado da vida

\footnotetext{
${ }^{28}$ MARX, ENGELS. Zur Kritik der Politischen Ökonomie. Berlin: MEW, Band 13, p. 9.

${ }^{29}$ MARX, ENGELS. Die Deutsche Ideologie. Berlin: MEW, Band 3, p. 28.

${ }^{30}$ MARX, ENGELS. Zur Kritik der Politischen Ökonomie. Berlin: MEW, Band 13, p. 8/9.

${ }^{31}$ MARX, ENGELS. Die Deutsche Ideologie. Berlin: MEW, Band 3, p. 37-38.

\begin{tabular}{|l|l|l|l|l|}
\hline Q Rovista Dialectus & Ano 3 & n. 8 & Janeiro - Agosto 2016 & p. 33-59 \\
\hline
\end{tabular}
}


comum, é o extra - o supraterrestre... Tais concepções puderam ver na história somente acontecimentos políticos relativos à ações do Estado e lutas religiosas e, principalmente, teóricas. Elas compartilham, assim, em cada época histórica das ilusões daquela época. ${ }^{32}$

Como observado acima, retomamos a perspectiva onto-epistemológica para seguir com a análise das relações entre Marx e Hegel. Para podermos examinar os textos de Marx a partir deste ponto de vista devemos assumir a hipótese de que estamos tratando com uma teoria que tem todas as características de estrutura, densidade, objeto e método, próprios de uma filosofia. Ao dizer isto estamos enunciado a primeira grande dificuldade enfrentada pelos críticos de Marx. Ao não encontrar no marxismo as formas que constituem a filosofia clássica - a metafísica - o pensamento de Marx foge ao entendimento crítico e permite as muitas interpretações contraditórias, incompletas, inconsistentes, com as quais nos deparamos a todo o momento.

Se Marx não é o primeiro crítico da metafísica, ele tem o mérito de ser o mais radical de todos os críticos desde o nascimento da filosofia no período clássico da cultura grega. Marx tem a característica de ser não-metafísico e anti-metafísico, porém sem perder contato com a metafísica, que é o alvo permanente de sua crítica.

Enquanto filosofia, o marxismo constrói sua crítica da metafísica a partir de uma visão de mundo materialista e dialética, voltada para a prática política como instrumento de libertação do homem, considerado na sua especificidade de animal social, político e racional. Neste sentido, as referências mais próximas para Marx, porque as mais elaboradas e desenvolvidas, aquelas que até o seu tempo levaram às últimas consequências as implicações da metafísica, da ordem política e da economia, em todas as suas dimensões foram: a filosofia clássica alemã, que tem em Hegel o seu maior representante, o pensamento político francês, que tem em Proudhon $(1809$ - 1865) um de seus expoentes mais destacados, e o pensamento da economia política clássica, presente nas obras de Adam Smith (1723 - 1790) e David Ricardo (1772 - 1823).

Seria equivocado, no entanto, pensarmos que, ao dialogar com a filosofia, Marx se reporte somente a Hegel, muitos outros pensadores fazem parte do amplo acervo de contribuições que concorrem para a construção da teoria crítica marxista. Só para lembrar, o maior destaque na obra principal de Marx - O Capital - são as abundantes referências a Aristóteles (384 - 322).

${ }^{32}$ MARX, ENGELS. Die Deutsche Ideologie. Berlin: MEW, Band 3, p. 39.
\begin{tabular}{|l|l|l|l|l|}
\hline Q Povista Wialectus & Ano 3 & n. 8 & Janeiro - Agosto 2016 & p. 33-59 \\
\hline
\end{tabular}




\section{Mais uma vez a relação Marx - Hegel}

Voltando ao nosso tema, observamos que não é este o momento de assumir as recomendações de Lenin $(1870-1924)^{33}$ para penetrarmos um pouco mais nos meandros do marxismo, ou seja, nos determos na filosofia, na economia política e no socialismo, como fontes do pensamento de Marx. Para seguirmos na análise das relações entre Marx e Hegel tomaremos um caminho que nos permite avançar de forma mais rápida e igualmente segura.

É nas primeiras páginas do Capital que Marx declara que recorre a Hegel porque foi ele quem apresentou, pela primeira vez, o método dialético de forma consciente e na sua mais ampla abrangência. ${ }^{34}$ Contudo, para Hegel, como já mencionamos, a dialética contém uma dimensão absoluta, ela ganha sua sustentação no Espírito absoluto, numa realidade abstrata, supra-humana. Em Hegel a dialética é uma sobredeterminação da existência. Em oposição, Marx assume a dialética como o modo de ser próprio da realidade - da natureza, da humanidade, do movimento da história.

Ao examinarmos a Ciência da Lógica - uma das principais obras de Hegel encontramos uma apresentação do método dialético como sendo expressão do autodesenvolvimento do conceito e também a forma do desenvolvimento da realidade. Isto nos põe diante da dialética a partir de uma perspectiva ontológica, teoricamente bem fundamentada. Decorre disso a afirmação hegeliana de que "O que é racional, isto é real, o que é real, isto é racional, 35 .

O que a crítica de Marx nos esclarece é que esta afirmação de Hegel significa definir uma relação dialética entre racionalidade e realidade, onde o principal aspecto não é o movimento em si, senão que muito mais o fato de que pelo seu desenvolvimento a realidade se realiza em direção a sua plenitude, em um processo teleológico sobredeterminado, enquanto que o conhecimento daquele processo é a apropriação do mesmo na forma de conceito, ou seja, uma operação de pensamento, teórica e não prática.

\footnotetext{
${ }^{33}$ LENIN. Drei Quellen und drei Bestandteile des Marxismus. Berlin: Dietz Verlag, Band 19, 1977, p. $3-9$

${ }^{34}$ MARX. Das Kapital. Berlin: MEW, Band 23, p. 27.

${ }^{35}$ HEGEL. Grundlinien der Philosophie des Rechts. Fankfurt am Main: Suhrkamp Verlag, Band 7, p.
} 24.

\begin{tabular}{|c|c|c|c|c|}
\hline Revista Q Dinlectus & Ano 3 & n. 8 & Janeiro - Agosto 2016 & p. 33-59 \\
\hline
\end{tabular}


É neste contexto que podemos situar e entender a consigna de Marx na sua $11^{\mathrm{a}}$ Tese contra Feuerbach, onde ele nos diz: “Os filósofos tem interpretado o mundo apenas de formas diferentes..." A dialética é para Hegel a autorrealização do pensar. Ela é o movimento através do qual nos apropriamos e entendemos a realidade nas suas estruturas necessárias. O ponto de partida é a sensação da existência do outro. $\mathrm{Ou}$, em outras palavras, na filosofia de Hegel o ponto de partida é uma realidade autônoma, à qual pode ser contraposta uma realidade distinta, uma nova realidade como sua negação. Esse movimento dialético avança na forma de permanentes negações - negação da negação - que se elevam a cada novo momento em direção à plena realização de um destino histórico onde, em seu télos, se unem um saber absoluto e uma realidade completamente desabrochada.

De suas notas de juventude, que conhecemos sob o título de Manuscritos Econômicos e Filosóficos, passando pela Ideologia Alemã, pela Crítica à Filosofia do Direito de Hegel, pela crítica a Ludwig Feuerbach, até O Capital, em nenhum momento encontramos Marx iludido pela filosofia de Hegel. Entretanto, como ele escreve ao seu amigo Joseph Dietzgen, em 9 de em maio de $1868^{36}$, as leis fundamentais da dialética já estão disponíveis no pensamento de Hegel, porém impregnadas de misticismo. Pouco antes, escrevendo a outro, entre os seus interlocutores mais frequentes, Marx já havia observado, na carta ao Dr. Kugelmann, de 6 de março do mesmo ano, que podia muito bem comprender o tom embaraçoso do senhor Dühring, com quem ele polemizava

naquele momento, pois ele, Dühring, segue Marx, "sabe muito bem que meu método de desenvolvimento não é hegeliano, uma vez que sou materialista e Hegel é idealista." 37

A dificuldade dos críticos de Marx está, entre outras, em interpretar corretamente passagens como a que encontramos no Capital, onde ele esclarece: “Aqui, como nas ciências naturais, comprova-se a exatidão da lei descoberta por Hegel em sua Lógica, de que modificações meramente quantitativas em certo ponto se transformam em diferenças qualitativas." 38

Já que os críticos de Marx se perdem na confusão de palavras, os conteúdos ficam ainda mais distantes de um entendimento, mesmo que elementar. Poderíamos nos

\footnotetext{
${ }^{36}$ MARX. Briefe an Joseph Dietzgen (9. Mai 1868). Berlin: MEW, Band 32, p. 547.

${ }^{37}$ MARX. Briefe an Ludwig Kugelmann (6. M6arz 1868). Berlin: MEW, Band 32, p. 538.

${ }^{38}$ MARX. Das Kapital. Berlin: MEW, Band 23, p. 327.

\begin{tabular}{|c|c|c|c|c|}
\hline Rovista Dialectus & Ano 3 & n. 8 & Janeiro - Agosto 2016 & p. 33-59 \\
\hline
\end{tabular}
}


estender por páginas e páginas de citações da obra de Marx, onde a dialética marxista, como método de análise e construção do conhecimento crítico da realidade, tem sua expressão clara e contundente, mas, exatamente por sua novidade e radicalidade, permanece além da compreensão daqueles que, formados em uma cultura metafísica, resistem em se desfazer de seus pré-conceitos.

Talvez a passagem do Capital que tem causado maior polêmica sobre a relação entre Marx e Hegel não esteja no texto da obra, mas no posfácio à segunda edição, a de janeiro de 1873. Assim, vale trazer aqui uma longa citação. Diz Marx: "Ao descrever de modo tão acertado e, tanto quanto entra em consideração a minha aplicação pessoal do mesmo, de modo tão benévolo aquilo que o autor chama de "meu verdadeiro método”, o que descreveu ele senão o método dialético?" (Marx está se referindo a uma recensão do I volume do Capital publicada em São Petersburgo em 1872).

É, sem dúvida, necessário distinguir o método de exposição formalmente do método de pesquisa. A pesquisa tem de captar detalhadamente a matéria, analisar as suas várias formas de evolução e rastrear sua conexão íntima. Só depois de concluído esse trabalho é que se pode expor adequadamente o movimento real. Caso se consiga isso, e espelhada idealmente agora a vida da matéria, talvez possa parecer que se esteja tratando de uma construção a priori. Por sua fundamentação, meu método dialético não só difere do hegeliano, mas é também a sua antítese direta. Para Hegel, o processo de pensamento, que ele, sob o nome de ideia, transforma num sujeito autônomo, é o demiurgo do real, real que constitui apenas a sua manifestação externa. Para mim, pelo contrário, o ideal não é nada mais que o material, transposto e traduzido na cabeça do homem. Há quase trinta anos, numa época em que ela ainda estava na moda, critiquei o lado mistificador da dialética hegeliana. Quando eu elaborava o primeiro volume de O Capital, epígonos aborrecidos, arrogantes e medíocres, que agora pontificam na Alemanha culta, se permitiam tratar Hegel como o bravo Moses Mendelssohn tratou Espinosa na época de Lessing, ou seja, como um "cachorro morto". Por isso, confessei-me abertamente discípulo daquele grande pensador e, no capítulo sobre o valor, até andei namorando aqui e acolá os seus modos peculiares de expressão. A mistificação que a dialética sofre nas mãos de Hegel não impede, de modo algum, que ele tenha sido o primeiro a expor as suas formas gerais de movimento, de maneira ampla e consciente. É necessário invertê-la, para descobrir o cerne racional dentro do invólucro místico. Em sua forma mistificada, a dialética foi moda alemã porque ela parecia tornar sublime o existente. Em sua configuração racional, é um incômodo e um horror para a burguesia e para os seus porta-vozes doutrinários, porque, no entendimento positivo do existente, ela inclui ao mesmo tempo o entendimento da sua negação, da sua desaparição inevitável; porque apreende cada forma existente no fluxo do movimento, portanto também com seu lado transitório; porque não se deixa impressionar por nada e é, em

\begin{tabular}{|l|l|l|l|l|}
\hline Q Povista Dialectus & Ano 3 & n. 8 & Janeiro - Agosto 2016 & p. 33-59 \\
\hline
\end{tabular}


sua essência, crítica e revolucionária. O movimento, repleno de contradições, da sociedade capitalista faz-se sentir ao burguês prático de modo mais contundente nos vai e vens do ciclo periódico que a indústria moderna percorre e em seu ponto culminante - a crise geral. Esta se aproxima novamente, embora ainda se encontre nos estágios preliminares, e, tanto pela sua presença por toda parte quanto pela intensidade de seus efeitos, há de enfiar a dialética até mesmo na cabeça dos parasitas afortunados do novo Sacro Império TeutoPrussiano. ${ }^{39}$

Voltando um pouco a um momento pretérito do pensamento de Marx, encontramos na introdução do texto Para a crítica da Economia Política o que consideramos a mais radical e definitiva ruptura com a metafísica, com o idealismo, e, por fim, com Hegel. Referimo-nos a conhecida afirmação de Marx, já citada acima: "Não é a consciência dos homens que determina sua existência, senão que, ao contrário, é a sua existência que determina sua consciência". Nada mais distante da filosofia de Hegel, desde um ponto de vista ontológico, do que esta expressão de entendimento da realidade. Este é um dos momentos em que fica evidente o que Marx pretende nos dizer quando afirma que é necessário inverter o pensamento de Hegel, que sua dialética, que se apoia sobre a cabeça, deve ser posta sobre seus pés, pois só assim ela terá os pés sobre a terra, estará apoiada na existência objetiva, na materialidade da vida.

Para concluir, nos propomos a examinar mais um conceito. Certamente haveria muitos outros além do qual vamos tratar e nossa escolha se deve ao fato de que há frequentes confusões em relação ao mesmo.

Queremos nos referir ao conceito de trabalho.

Muitos autodeclarados hegelianos, como da mesma forma, muitos autodeclarados marxistas, parecem desconsiderar o fato de que tanto Hegel como Marx percorreram muitas partes comuns dos caminhos abertos pelos mais de dois mil anos de história do pensamento ocidental. Assim, encontramos tanto em Hegel quanto em Marx referências e remissões aos clássicos gregos, e entre eles, em especial a Platão e Aristóteles. Ambos examinaram com argúcia também o pensamento dos fundadores do pensamento político moderno de Maquiavel (1469 - 1527) a Rousseau (1712 - 1778), incluindo-se aí Hobbes (1588 - 1679), Locke (1632 - 1704) e Kant, para só citar

${ }^{39}$ MARX. Das Kapital. Berlin: MEW, Band 23, p.27-28.

\begin{tabular}{|l|l|l|l|l|}
\hline Q Rovista Qialectus & Ano 3 & n. 8 & Janeiro - Agosto 2016 & p. 33-59 \\
\hline
\end{tabular}


alguns. Ambos se detiveram nos doutores da Igreja, com destaque para Santo Augustinho (354 - 430) e Santo Tomas (1225 - 1274). Se nós podemos supor que Marx conhecia muito bem os pais da economia moderna, Adam Smith e David Ricardo, Thomas Malthus (1766 - 1834), William Petty (1623 - 1687), entre outros, a leitura destes clássicos também ocupou demoradamente a Hegel.

Resgatado o conteúdo do conceito de trabalho da tradição grega, sem entrar em maiores detalhes, se pode dizer que nele estão contidos alguns elementos que, tendo passado por Hegel, chegaram até Marx. Queremos nos referir a trabalho como energia, como força, como capacidade de modificar algo, de construir algo a partir de uma matéria prima, de transformar algo, de intervir num processo, de modificar algo na e da natureza $^{40}$. Trabalho para os gregos é, como disse mais tarde Michelangelo (1475 1564), a ação de retirar do bloco de mármore o que está sobrando, o que não pertence à figura de Davi. Trabalho, repetimos, requer força, mas também criação, ou seja, não é só músculo, é razão, racionalidade, e mais ainda, liberdade ${ }^{41}$.

Com os gregos, Hegel observa que o oleiro faz o pote e o pote, por sua vez, faz o oleiro $^{42}$. Marx, depois de ter percorrido os mesmos pensadores que Hegel, coincide com ele em todas estas dimensões do conceito de trabalho. Mesmo quando Marx nos fala de trabalho alienado ele não está distante da perspectiva hegeliana. A dialética do servo e do senhor na Fenomenologia do Espírito ${ }^{43}$ é para Marx um lugar privilegiado da construção das relações entre trabalho, alienação e liberdade. Mas, depois de dito tudo isto devemos concluir que Marx continua com Hegel até as últimas consequências do conceito de trabalho? Certamente que não. Mas, talvez não, por motivos bastante distintos daquele que nos apontam alguns críticos do marxismo ${ }^{44}$.

A ruptura entre Marx e Hegel está no fato de que o trabalho é para Marx um duplo instrumento de liberdade. O trabalho liberta enquanto dá ao homem a dimensão de suas potencialidades diante da natureza; o homem tem a capacidade de conhecer, de construir um projeto e executá-lo, submetendo a natureza as suas necessidades e

${ }^{40}$ ENGELS. Briefe an Marx (19. Dezember 1882). Berlin: MEW, Band 35, p. 133-35.

${ }^{41}$ MARX. Ökonomisch-philosophische Manuskripte (1844). Berlin: MEW, Ergänzunsband - Ester Teil,

p. $510-522$.

${ }^{42}$ HEGEL. Vorlesung über die Ästhetik. Fankfurt am Main: Suhrkamp Verlag, Band 13, p. 51.

${ }^{43}$ HEGEL. Phenomenologie des Geistes. Fankfurt am Main: Suhrkamp Verlag, Band 3, p. 145 - 155.

MARX. Kritik der Hegelschen Dialektik und Philosophie überhaupt. Berlin: MEW, Band 40, p. 574.

${ }^{44}$ MARX. Neue Rheinische Zeitung, Lohnarbeit und Kapital. Berlin: MEW, Band 6, p. $407-408$.

\begin{tabular}{|c|c|c|c|c|}
\hline Qenista Dialectus & Ano 3 & n. 8 & Janeiro - Agosto 2016 & p. 33-59 \\
\hline
\end{tabular}


vontades. O trabalho liberta o homem ainda porque ele é um instrumento de luta política, de luta revolucionária, de emancipação frente àqueles que o dominam e exploram, comprando sua força de trabalho por um valor inferior ao que ela produz ${ }^{45}$. Marx não compartilha da visão romântica de que o trabalho enobrece. Na sociedade de classes o trabalho tem uma realidade dialética, nos ensina Marx. De um lado ele é instrumento de exploração, contudo, de outro ele é instrumento de luta, de conquista de liberdade.

É por isto que Marx e Engels encerram o Manifesto do Partido Comunista de 1848 dizendo: "Temam as classes dominantes diante de uma revolução comunista. Os proletários não têm nada a perder além de seus grilhões, eles tem o mundo a ganhar. Proletários de todos os países, uni-vos!" 46

Referências

COLlingWOOD, R.G. A ideia de História. Lisboa: Editorial Presença, 2001.

DARWIN, Ch. A Origem das Espécies. Rio de Janeiro: Ediouro, 2004.

ENGELS, F. Anti-Dühring. Berlin: MEW, Bd. 20, 1971.

. Dialektik der Natur. Berlin: MEW, Bd. 20,1971.

. Briefe an Marx (19. Dezember 1882). Berlin: MEW, Bd. 35, 1971.

FICHTE, I.H. Zur Politik, Moral und Philosophie. In: Fichtes Werke Bd. VII. Bonn: Walter Gruyter \& Co, 1971.

HEGEL, G.W.F. Phenomenologie des Geistes. Fankfurt am Main: Suhrkamp Verlag, Bd. 3, 1969.

$6,1969$.

Wissenschaft der Logik II, Fankfurt am Main: Suhrkamp Verlag, Bd.

- Grundlinien der Philosophie des Rechts. Fankfurt am Main:

Suhrkamp Verlag, Bd. 7, 1969.

Enzyklopädie der philosophischen Wissenschaften II. Fankfurt am Main: Suhrkamp Verlag, Bd. 9, 1969.

Bd. 13, 1969.

Vorlesung über die Ästhetik. Fankfurt am Main: Suhrkamp Verlag,

\footnotetext{
${ }^{45}$ MARX. Brief an das Arbeiterparlament ( 9.März 1854). Berlin: MEW, Band 10, p.126.

${ }^{46}$ MARX, ENGELS. Manifest der Kommunistischen Partei. Berlin: MEW, Band 4, p. 493.

\begin{tabular}{|c|c|c|c|c|}
\hline Qenista Dialectus & Ano 3 & n. 8 & Janeiro - Agosto 2016 & p. 33-59 \\
\hline
\end{tabular}
}


Vorlesungen über die Philosophie der Religion I. Fankfurt am Main: Suhrkamp Verlag, Bd. 16, 1969.

Vorlesungen über die Geschcihte der Philosophie II. Fankfurt am Main: Suhrkamp Verlag, Bd. 19, 1969.

HYPPOLITE, J. Ruse de la raison et histoire chez Hegel. In: Figure de la pensée philosophique. Paris: PUF, 1971.

INWOOD. M. Dicionário Hegel. Rio de Janeiro: Jorge Zahar Editor, 1997.

KIMMERLE, Heinz (Hrsg). Modelle der materialistischen Dialektik - Beiträge der Bochumer Dialektik-Arbeitsgemeinschaft. Den Haag: Martius Nijhoff, 1978.

LAUTH, Reihard. Der Begriff der Geschcichte nach Fichte. In: Philosophisches Jahrbuch, 72 - (1964/65).

LEFEBVRE, H. La fin de l'histoire. Paris: Les Éditions de Minuit, 1970.

LENIN, V.I. Drei Quellen und drei Bestandteile des Marxismus. Berlin: Dietz Verlag, Bd. 19, 1977.

MARX, K.; ENGELS, F. Die deutsche Ideologie. Berlin: MEW, Bd. 3. 1971.

4, 1971. . Manifest der Kommunistischen Partei. Berlin: MEW, Bd.

$13,1971$.

Zur Kritik der Politischen Ökonomie. Berlin: MEW, Band

Mathematische Manuskripte.Wolfgang Endmann (Hrsg.).

Kronberg: Scriptor Verlag, 1974.

MARX, Karl. Ökonomisch-philosophische Manuskripte (1844). Berlin: MEW, Ergänzunsband - Ester Teil, 1971.

Band 6, 1971.

Neue Rheinische Zeitung, Lohnarbeit und Kapital. Berlin: MEW,

Brief an das Arbeiterparlament ( 9.März 1854). Berlin: MEW,

Bd.10, 1971.

Das Kapital I. Berlin: MEW, Bd. 23, 1971.

Briefe an Joseph Dietzgen (9. Mai 1868). Berlin: MEW, Band 32,

1971.

\begin{tabular}{|c|c|c|c|}
\hline Rovista Dialectus & Ano 3 & n. 8 & Janeiro - Agosto 2016 \\
\hline
\end{tabular}


$32,1971$.

Briefe an Ludwig Kugelmann (6. M6arz 1868). Berlin: MEW, Band

Kritik der Hegelschen Dialektik und Philosophie überhaupt. Berlin:

MEW, Bd. 40, 1971.

POPPER, K. Das Elend des Historizismus. Tübingen: Mohr Siebck Verlag, 2003.

Verlag, 2003.

Die offene Gesellschaft und ihre Feinde. Tübingen: Mohr Siebck

RUBEN, P. Methodologische Bemerkungen zur Beziehungen zwischen Logik und Dialektik bei Hegel und Marx. Online-Edition peter-ruben.de.

SARTRE, Jean-Paul. Critique de la raison dialectique. Paris: Librairie Gallimard, 1960.

SCWARZ, Th. J.-P. Sartre et le marxisme. Réflexions sur la Critique de la raison dialectique. Lousanne: L'Âge de 1’Homme, 1976.

SCHELling, F.W.J. Grundlegung der Positiven Philosophie. Torino: Bottega D’Erasmo, 1972.

STICH, H. Von Herds "Ideen zur Philosophie der Geschichte der Mensacheit" über Kant, Fichte, Schelling bis zu Hegels Vorlesungen über Philosophie der Geschichte. Ein Beitrag zur Philosophie der Geschichte. Wien, Philosophische Diskussion, 1936 (mimeo).

WAGENKNECHT, S. Vom Kopf auf die Füße? Zur Hegelkritik des jungen Marx oder das Problem einer dialektisch-materialistischen Wissenschaftstheorie. Bonn: Pahl-Rugenstein Verlag, 1997.

WOLF, D. Hegel und Marx. Zur Bewegungsstruktur des absoluten Geistes und des Kapital. Hamburg: VSA - Verlag, 1979. 